Journal of Applied Pharmaceutical Science Vol. 5 (08), pp. 143-146, August, 2015

Available online at http://www.japsonline.com

DOI: $10.7324 / \mathrm{JAPS} .2015 .50822$

ISSN 2231-3354 (cc) BY-NC-SA

\title{
The effect of non-compliance of PPI instruction on the stability of reconstituted oral antibiotics
}

\author{
Murad Abualhasan ${ }^{1 *}$, Mashhour M. Ghanem ${ }^{2}$, Mohyeddin Assali ${ }^{1}$, Abdel Naser Zaid ${ }^{1}$ \\ ${ }^{1}$ Department of Pharmacy, An-Najah National University, Nablus, Palestine. \\ ${ }^{2}$ Pharmacare pharmaceutical Company, P.O. Box 677, Ramallah, Palestine.
}

\begin{tabular}{l} 
ARTICLE INFO \\
\hline Article history: \\
Received on: $31 / 03 / 2015$ \\
Revised on: 09/04/2015 \\
Accepted on: $28 / 04 / 2015$ \\
Available online: $28 / 08 / 2015$ \\
\hline Key words: \\
PPI, antibiotics, storage \\
conditions, reconstituted oral \\
suspensions.
\end{tabular}

\begin{abstract}
The patient package inserts (PPIs) should contain all the required information for the patient. It must be clear and understandable. There are several problems with the PPIs including the wrong information, readability and comprehensibility. Thus the pharmacists have to take an active role in making sure that patient is aware of important instruction including correct storage. Five antibiotics namely Erythromycin ethylsuccinate, Amoxicillin, Cefdinir, Flucloxacillin sodium and Clarithromycin powder for suspensions, were selected for this study, these antibiotic were reconstituted as directed on the label and tested initially and after 7 days when stored at room temperature and in refrigerator. Several chemical and physical pharmacopeial tests were performed. The results showed that two of the antibiotic oral suspensions namely erythromycin ethyl succinate and flucloxacillin sodium failed the accepted shelf life specification limits when stored at room temperature while both passes these limits when stored in refrigerator. Erythromycin ethylsuccinate has failed the tests of taste and odour while the flucloxacillin sodium has failed the assay test. Clarithromycin has failed some tests as viscosity, taste and pouring test when stored in refrigerator while passes all the tests when stored at room temperature. The study showed the vital role of the pharmacist to reiterate the important patient package insert instructions specially those concerned with the storage condition of the drug.
\end{abstract}

\section{INTRODUCTION}

The patient package inserts (PPIs) should by law be in the packaging of drugs and should contain all the required information for the patient. The leaflet provides a readily information on drugs for patients (FDA (1998). The PPIs must be clear and understandable to the general population (Rowe, 1995; Sansgiry et al., 1997). The PPIs should instruct the patient for safe and correct use of the medication. The majority of international regulatory affairs recommend that all marketed medications must be supplied with a PPI that is written in both local language and English (Sansgiry et al., 1997; Wallace et al., 2008). Despite efforts to improve the readability and comprehensibility, by both the drug regulatory authorities and the manufactures, package inserts still have an extensive volume of incomprehensible text and the small font size used, which people make for an ordinary patient distressing (Al-Ramahi et al.; George et al., 1983; Sansgiry et al., 1997; Traynor, 2009).

\footnotetext{
* Corresponding Author

Murad N Abualhasan, Department of Pharmacy, An-Najah National

University, Nablus, Palestine.Email: m_abualhasan@najh.edu
}

Thus it is important that pharmacists and pharmacy technicians take an active role in making sure that paediatric suspensions are prepared, dispensed and stored correctly. Improper mixing and storage after reconstitution of antibiotic suspensions is a source of medication errors in paediatric patients(Naidoo et al., 2006; Watson and Barash, 2009). Some of the reconstituted antibiotics must be refrigerated which is required for stability or to prevent microbial growth or just to improve taste(Uzunović and Vranić, 2008). However, some reconstituted antibiotics are clearly instructed in the leaflet not be refrigerated due to the loss in potency or just gets hard to pour (letters, 2008). The pharmacist has a vital role in assuring that the volume of water required to be added, which is listed on the bottle label and leaflet, the pharmacist must emphasize on the written instruction about the water used to reconstitute powders for suspension whether a distilled or purified. Water from the tap has fluoride and other contaminants that may not be desirable. When it is instructed in the leaflet about the amount of water need to be added it must be measured; the pharmacist must notify patient about the appropriate measuring device to use for the best accuracy (Kessler, 1991; Shiffman et al., 1345; Shrank and Avorn, 2007). In this study we 
are going to investigate the stability of selected reconstituted antibiotic in which it is clearly instructed in the package insert that to be stored either in refrigerator or at room temperature after reconstitution. The aim of this study was to check both the chemical and physical change that may occur on the drug if the patient was not aware of the instruction stated in the leaflet and the drug was stored wrongly at room temperature or in the refrigerator after reconstitution. The result of this study will increase awareness to both the pharmacist as well as the patient of careful reading and strictly following of the instruction.

\section{MATERIAL AND METHOD}

\section{Reagents}

Reference standards of amoxicillin, cefdinir, fluocloxacillin sodium, erythromycin ethylsuccinate, and clarithromycin were supplied by pharmacare-PLC. USP Cefdinir related compound A and USP Cefdinir Related compound B were used. HPLC grade methanol and acetonitril solvents, Ammonium acetate extra pure, monobasic potassium phosphate, anhydrous dibasic sodium phosphate, potassium hydroxide pellets, sodium hydroxide, phosphoric acid, disodium ethylenediaminetetraacetate, tetramethylammonium hydroxide and tetrahydrofuran were purchased from reliable sources like Merck, Germany. High Purified water was prepared by using a Millipore Milli-Q plus water purification system.

\section{Instrumentation}

The HPLC system consisted of LaChrom (MerckHitachi) equipped with model L-7100 pump, L-7200 autosampler, L-7300 column oven, DAD L-7450 photo diode array (PDA) detector and D-7000 software HSM version 3.1 (Merck Hitachi, England) was used. A double beam ultraviolet-visible spectrometer (PG Instruments, United Kingdom) was also used. Dissolution apparatus (Erweka DT6, Germany), other instruments used including viscometer (Brookfield DV-II) and Mettler Toledo pH meter MP230.

\section{Procedure}

Five antibiotics namely Erythromycin ethylsuccinate, Amoxicillin, Cefdinir and Flucloxacillin sodium and clarithromycin oral suspensions were selected for this study, these antibiotics were locally manufactured and widely sold in the local Palestinian community and ministry of health pharmacies. The package insert of these antibiotic clearly state that some of them should be stored in refrigerator after reconstitution while others can be stored at room temperature and others should not be stored in refrigerator and all should not be used more than seven days after reconstitution. Three batches of each oral suspension were randomly selected for analysis and were reconstituted in accordance to the leaflet instruction. All the antibiotics were tested initially to ensure that all the tests are within the acceptable limits. Several pharmacopeial tests were carried out on each of the oral suspensions after reconstitution, these tests include three batches: percentage assay, precipitation, colour, taste, odour, viscosity, pouring test, redispersion test, $\mathrm{pH}$ and microbial contamination. These tests were carried out according to USP procedure (USP, 2009); the tests were done immediately after reconstitution and then repeated 7 days after reconstitution when stored at room temperature and when stored in refrigerator.

\section{RESULT}

The results show that the percentage assay tests of the oral antibiotics of Cefdinir (96.9\%), Erythromycin ethylsuccinate (99.4\%), Amoxicillin (102.1\%), Flucloxacillin sodium (101.5\%) and Clarithromycin oral suspension(98.7) were within the limits after 7 days when stored in refrigerator (Table 1 to 4).

However, the assay test results were decreased after 7 days of reconstitution when stored at room temperature but still within the acceptable limits for oral antibiotics Cefdinir (95.2\%), Erythromycin ethylsuccinate $(95.3 \%)$, Amoxicillin $(98.4 \%)$ and Clarithromycin $(98.1 \%)$. The percentage assay of reconstituted oral suspension of flucloxacillin sodium was lower and failed the limit $(89.9 \%)$ when stored at room temperature as shown in (Table 3). The study also shows that erythromycin ethylsuccinate has failed the taste and odour tests within 7 days when stored at room temperature (Table 4). The results show that erythromycin suspension became bitter in taste and has developed an unacceptable odour. The tests of reconstituted clarithromycin oral suspension when stored at refrigerator showed failure of the viscosity parameter and consequently affected the pouring test and render it not comply specification limit test. Moreover, the refrigerated clarithromycin failed the taste test which became bitter and acceptable (Table 5). In all the above mentioned antibiotics; all the other pharmacopeial and non pharmacopeial tests were within the acceptable limits these test include: the dissolution, redispersion, $\mathrm{pH}$ and microbial limit test.

\section{DISCUSSION}

The results showed only one failure in percentage assay of the Flucloxacillin sodium reconstituted oral suspension when stored at room temperature (Table 3), but the other reconstituted antibiotics that stored at room temperature showed decrease in the percentage assay of active ingredient for Cefdinir, Erythromycin ethylsuccinate and amoxicillin. Even though they were within the acceptable limit but the decrease is alarming particularly when people wrongly store their drug at temperature higher than the room temperature, this indicates that there is a high possibility that the percentage assay of that active ingredient of the oral suspension antibiotics will dramatically decrease and fail the assay acceptable limits. In the contrary to the above mentioned antibiotics; the PPI of clarithromycin oral suspension storage instruction states that the reconstituted oral suspension should not be refrigerated and rather should be stored at room temperature. 
Table 1: Chemical and physical tests results of reconstituted cefdinir powder for oral suspension .

\begin{tabular}{|c|c|c|c|}
\hline Tests & After 7 days in refrigerator & After 7 Days at room temperature & Limit \\
\hline Color & Complies & Complies & Off-white to cream colored suspension \\
\hline Odor & Complies & Complies & Strawberry \\
\hline Taste & Complies & Complies & Strawberry \\
\hline Pouring Test & Complies & Complies & Smooth and easy \\
\hline Viscosity & 338 & 275.0 & 200-500 mpa.s \\
\hline pH & 4.24 & 4.17 & $3.5-4.5$ \\
\hline Redispersion test & Complies & Complies & Easy redispersion . \\
\hline Assay of Cefdinir & 96.9 & 95.2 & $90.0-110.0 \%$ \\
\hline Average dissolution & 99.8 & 100.6 & Minimum $85.0 \%(\mathrm{Q}=80 \%)$ \\
\hline Total impurities & $4.32 \%$ & $4.97 \%$ & NMT $6.2 \%$ \\
\hline Total aerobic microbial count & $<10$ & $<10$ & Max. $100 \mathrm{cfu} / \mathrm{ml}$ \\
\hline
\end{tabular}

Table 2: The chemical and physical tests results of reconstituted amoxicillin powder for oral suspension.

\begin{tabular}{|c|c|c|c|}
\hline Tests & After 7 days in refrigerator & After 7 Days at room temperature & Limit \\
\hline \% Assay amoxicillin & 102.1 & 98.4 & $(90.0-120.0) \%$ \\
\hline Identification & Complies & Complies & HPLC (Rt) \\
\hline Taste & Complies & Complies & Banana and vanilla like \\
\hline Odor & Complies & Complies & Banana and vanilla like \\
\hline Color & Complies & Complies & Pale yellow \\
\hline Precipitation & Complies & Complies & No ppt. found within $2 \mathrm{~h}$ \\
\hline Pouring Test & Complies & Complies & Smooth and easy \\
\hline Viscosity & 540 & 430 & 300-1000 mpa.s \\
\hline Redispersion & Complies & Complies & Easy Redispersion \\
\hline pH & 6.7 & 6.9 & $5.0-7.5$ \\
\hline Total aerobic microbial count & $<10$ & $<10$ & Max $100 \mathrm{cfu} / \mathrm{ml}$ \\
\hline
\end{tabular}

Table 3: The chemical and physical tests results of reconstituted Flucloxacillin powder for oral suspension.

\begin{tabular}{|c|c|c|c|}
\hline Tests & After 7 days in refrigerator & After 7 Days at room temperature & Limit \\
\hline \% assay flucloxacillin sodium & 101.5 & 89.9 & $90.0-120.0 \%$ \\
\hline Identification & Complies & Complies & HPLC (Rt) \\
\hline Color & Complies & Complies & Red suspension \\
\hline Odor & Complies & Complies & Tutti fruiti like odor \\
\hline Taste & Complies & Complies & Tutti fruiti like taste \\
\hline pH & 6.53 & 6.49 & 5.0 and 7.0 \\
\hline Sedimentation Volume & 1.0 & 1.0 & Min. 0.95 \\
\hline Precipitation & Complies & Complies & No ppt. found within $2 \mathrm{~h}$ \\
\hline Pouring Test & Complies & Complies & Smooth and easy \\
\hline Viscosity & 680 & 510 & 300-1000 mpa.s \\
\hline Redispersion Test & Complies & Complies & No ppt. should remain \\
\hline viable aerobic count & $<10$ & $<10$ & Max. 100cfu/ml \\
\hline
\end{tabular}

Table 4: The chemical and physical tests results of reconstituted erythromycin ethylsuccinate powder for oral suspension.

\begin{tabular}{|c|c|c|c|}
\hline Tests & After 7 days in refrigerator & After 7 Days at room temperature & Limit \\
\hline \% Assay Erythromycin & 99.4 & 95.3 & $90.0-120.0 \%$ \\
\hline Identification & Complies & Complies & TLC (Rf) \\
\hline Odor & Comply & Not-Comply & Strawberry \\
\hline Taste & Comply & Bitter Taste (Not-Comply) & Strawberry \\
\hline Color & Complies & Complies & Pink suspension \\
\hline Precipitation & Complies & Complies & No ppt. found within $2 \mathrm{~h}$ \\
\hline Pouring Test & Complies & Complies & Smooth and easy \\
\hline Redispersion & Complies & Complies & Easy Redispersion \\
\hline pH & 7.78 & 7.72 & $7.0-9.0$ \\
\hline Sedimentation Volume & 0.99 & 1.0 & Min. 0.95 \\
\hline Viscosity & 1486 & 1209 & $700-2000 \mathrm{cps}$ \\
\hline Total aerobic microbial count & $<10$ & $<10$ & Max $100 \mathrm{cfu} / \mathrm{ml}$ \\
\hline
\end{tabular}

Table 5: Chemical and physical tests results of reconstituted clarithromycin powder for oral suspension.

\begin{tabular}{|c|c|c|c|}
\hline Tests & After 7 days in refrigerator & After 7 Days at room temperature & Limit \\
\hline Color & Complies & Complies & White to off white colored suspension \\
\hline Odor & Complies & Complies & Peach to orange odor \\
\hline Taste & Bitter taste & Complies & Peach to orange taste \\
\hline Pouring Test & Difficult & Complies & Smooth and easy \\
\hline Viscosity & 860 & 275.0 & $250-450$ cps. \\
\hline pH & 4.9 & 5.0 & $4.0-5.4$ \\
\hline Redispersion test & Complies & Complies & Easy redispersion. \\
\hline Identification & Complies & Complies & HPLC (Rt) \\
\hline Assay of Clarithromycin & 98.7 & 98.1 & $90.0-115.0 \%$ \\
\hline Total aerobic microbial count & $<10$ & $<10$ & Max. $100 \mathrm{cfu} / \mathrm{ml}$ \\
\hline
\end{tabular}


The results as shown in Table 5 indicate the is a failure of some physical tests including the viscosity, pouring test and taste. The viscosity is an important parameters that is affected when the suspension is wrongly stored in the refrigerator this caused a high increase in the viscosity and as a result of increased viscosity the pouring property of the oral becomes not easy ; this may lead to incorrect dosing for the patient. Moreover, high viscosity will affect the absorbitivity of the drug and will also cause the clarithromycin to stay more time in the mouth when administered by the patient and thus increase the feeling of the bitter taste. However, when the reconstituted clarithromycin oral suspension was stored at room temperature all the testes were within specification limits. There is a wrong common belief among community patients that all the reconstituted drugs must be stored in refrigerator after reconstitution. This is not the case for some macrolids antibiotic such as clarithromycin which are chemically more stable than the penicillin antibiotics which have an easily hydrolysable beta lacatum ring, thus assay of clarithromycin is not affected when the product is stored at room temperature while penicillin must be stored in refrigerator.

The results clearly show that wrong storage will affect some physical and chemical test, and hence the role of pharmacist is to emphasize to the patient the necessity of keeping the reconstituted oral suspension in correct storage temperature and the not more than the allowed period. Overall, the pharmacist has to advice the patient of reading the drug insert, but at the same time has to reiterate the important instruction including the storage temperature of the dispensed drug.

\section{CONCLUSION}

The study was performed on five selected reconstituted oral antibiotics. The results showed that the assay and some physical parameters are affected and render the drug out of the pharmacopeial limits when the reconstituted drug was stored in the wrong condition. The study showed the vital role of the pharmacist to reiterate the important patient package insert instructions specially those concerned with the storage condition of the drug.

\section{ACKNOWLEDGEMENT}

This article does not contain any studies with human and animal subjects performed by any of the authors. All authors declare that they have no conflict of interest.

\section{REFERENCES}

Al-Ramahi, R., Zaid, A. N., Kettana, N., Sweileh, W., and AlJabi, D. Attitudes of consumers and healthcare professionals towards the patient package inserts - a study in Palestine. Pharm Pract, 2012; 10, 57 63.

FDA. 1998. Prescription drug product labeling; medication guide requirements--FDA. Final rule. Fed Regist 63, 66378-400.

George, C. F., Waters, W. E., and Nicholas, J. A. Prescription information leaflets: a pilot study in general practice. Br Med J, 1983; 287, 1193-6.

Kessler, D. A. Communicating with patients about their medications. N Engl J Med, 1991; 325, 1650-2.

Chart: Stability of Refrigerated and Frozen Drugs. Pharmacist letters/ prescribers letters. 2008; 24, No. 241001.

Naidoo, K., Nompuku, P., Mkalali, S., K Shabangu, Nkabinde, L., and Singh, V. Post-marketing stability surveillance: Amoxicillin. South African Family Practice, 2006; 6.

Rowe, H. M. Patient package inserts: the proper prescription? Food Drug Law J, 1995; 50, 95-124.

Sansgiry, S. S., Cady, P. S., and Patil, S. Readability of overthe-counter medication labels. J Am Pharm Assoc, 1997; 5, 522-8.

Shiffman, S., Gerlach, K. K., Sembower, M. A., and Rohay, J. M. Consumer understanding of prescription drug information: an illustration using an antidepressant medication. Ann Pharmacother, 2011; $45,452-8$

Shrank, W. H., and Avorn, J. Educating patients about their medications: the potential and limitations of written drug information. Health Aff, 2007; 26, 731-40.

Traynor, K. Consumer medication leaflets inadequate, FDA says," Am J Health Syst Pharm. 2009; 66(3): 208-210.

United States Pharmacopeia and National Formulary (USP 33). Vol 2. Rockville, MD: United States Pharmacopeia Convention; 2009

Uzunović, A., and Vranić, E. Stability of cefuroxime axetile oral suspension at different temperature storage conditions Bosnian journal of basic medical science, 2008; 8, 93-97.

Wallace, L. S., Keenum, A. J., Roskos, S. E., Blake, G. H., Colwell, S. T., and Weiss, B. D. Suitability and readability of consumer medical information accompanying prescription medication samples. Patient Educ Couns, 2008; 70, 420-5.

Watson, K. T., and Barash, P. G. The new Food and Drug Administration drug package insert: implications for patient safety and clinical care. Anesth Analg, 2009; 108, 211-8.

\section{How to cite this article:}

Murad Abualhasan, Mashhour M. Ghanem, Mohyeddin Assali, and Abdel Naser Zaid., The effect of non-compliance of PPI instruction on the stability of reconstituted oral antibiotics. J App Pharm Sci, 2015; 5 (08): 143-146. 